
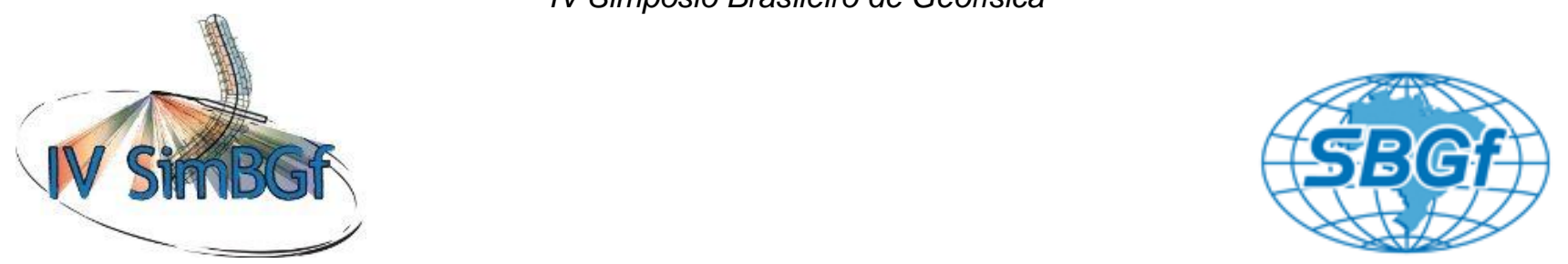

\title{
Aplicação do método da Eletrorresistividade em área de disposição de resíduos sólidos domiciliares
}

Mônica Teixeira de Oliveira* \& César Augusto Moreira Universidade Federal do Pampa - UNIPAMPA. Avenida Pedro Anunciação, s/n, Vila Batista, CEP 96570-000, Caçapava do Sul - RS

Copyright 2010, SBGf - Sociedade Brasileira de Geofísica

Este texto foi preparado para a apresentação no IV Simpósio Brasileiro de Geofísica, Brasília, 14 a 17 de novembro de 2010. Seu conteúdo foi revisado pelo Comitê Técnico do IV SimBGf, mas não necessariamente representa a opinião da SBGf ou de seus associados. É proibida a reprodução total ou parcial deste material para propósitos comerciais sem prévia autorização da SBGf.

\begin{abstract}
This study allowed an assessment of the degree of contamination, and also suggest measures for monitoring and remediation, by Electrical Resistivity method in waste landfill, located in the municipality of Caçapava do Sul RS. The waste landfill on Vacacaí Metamorphic Complex rocks that is locally characterized by amphibolite, micaschist and talc-schists. Were also performed 83 measurements of direction and sense of fractures. The results of resistivity are probably associated with the presence of leachate. There is a relationship between anomalous zones with the fracture directions measured in the field, other words, leachate accumulation in fracture zones.
\end{abstract}

\section{Introdução}

A poluição dos solos gera um grande problema para o meio ambiente, inclusive provoca grande impacto nas águas subterrâneas. Vários estudos têm sido realizados em áreas de deposição de resíduos sólidos, onde há suspeita de contaminação provocada pelo líquido proveniente da degradação de resíduos orgânicos, caracterizado por baixo $\mathrm{pH}$ e elevada demanda química e biológica por oxigênio. Tais características tornam o chorume um composto com caráter contaminante (HAMADA, 1999).

O gerenciamento de resíduos sólidos urbanos tem sido um verdadeiro desafio aos gestores públicos, devido a problemas como áreas disponíveis, licenciamento ambiental, custos de transporte, dentre outros.

A omissão dos órgãos de fiscalização ou o simples descaso da população, muitas vezes resultam no descarte clandestino de resíduos, geralmente em áreas inapropriadas, como nascentes, rios e áreas de proteção permanente.

Caso 0 solo sob os resíduos seja permeável e desprotegido, o chorume pode atingir o nível freático. A geração de chorume pode ultrapassar quinze anos após o final da deposição de lixo, dependendo de vários fatores (POSSAMAl et. al, 2007).

Atualmente os métodos geofísicos têm sido amplamente utilizados neste tipo de estudo devido a sua rapidez e custo relativamente baixo quando comparados a outras técnicas de investigação. Os principais métodos geofísicos para investigação de contaminantes são: Métodos de Eletrorresistividade, Métodos Eletromagnéticos, Potencial Espontâneo (SP), Radar de Penetração no Solo (GPR) e eventualmente Magnetometria (CETESB, 2001).

No aterro municipal de Cordeirópolis (SP) Moreira et al. (2009) utilizaram medidas de resistividade elétrica, obtidas com a técnica de Caminhamento Elétrico, combinadas com medidas de $\mathrm{pH}$ e $\mathrm{Eh}$ em amostras de solo para avaliar o comportamento geoquímico de resíduos sólidos enterrados, durante o processo de degradação de matéria orgânica. Os estudos foram realizados em valas fechadas entre 12/2001 a 12/2007. Os resultados mostraram a presença de valores de resistividade abaixo de $30 \Omega$ nas linhas realizadas sobre as valas, sugerindo a presença de chorume. A correlação temporal entre $\mathrm{pH}$ e Eh pode indicar as condições geoquímicas predominantes as quais estão associadas ao padrão de resistividade elétrica. Assim, baixos valores de resistividade associados a baixos valores de $\mathrm{pH}$ e elevados valores de Eh indicam a possível existência de uma pluma de contaminação.

Numa área do aterro controlado da cidade de Rio ClaroSP, Moura \& Malagutti (2003) aplicaram os métodos da Eletrorresistividade e Polarização Induzida com o objetivo de avaliar as potencialidades da integração dos métodos na caracterização geoelétrica da área. A base do aterro é constituída por arenitos cenozóicos pertencentes a Formação Rio Claro, que está, por sua vez, assentada discordantemente sobre siltitos da Formação Corumbataí. A interpretação conjunta da resistividade e da polarizabilidade, além de reduzir a ambigüidade dos modelos geoelétricos unidimensionais e bidimensionais interpretados, permitiu determinar a geometria das cavas de resíduos, zonas de percolação de chorume e identificar os diferentes litotipos das formações, identificando materiais arenosos e siltosos.

Este estudo visa realizar uma investigação geofísica numa área de disposição de resíduos sólidos domiciliares, no município de Caçapava do Sul, por meio do método da Eletrorresistividade.

Os objetivos são a definição da espessura de resíduos enterrados e a presença de caminhos preferenciais de fluxo associado ao fraturamento do substrato.

\section{Caracterização da área de estudo}

À área de estudos foi um local de disposição de resíduos sólidos domiciliares, localizado no Rincão dos Bitencourt, zona rural do município de Caçapava do Sul, RS, Brasil (Figura 1). 


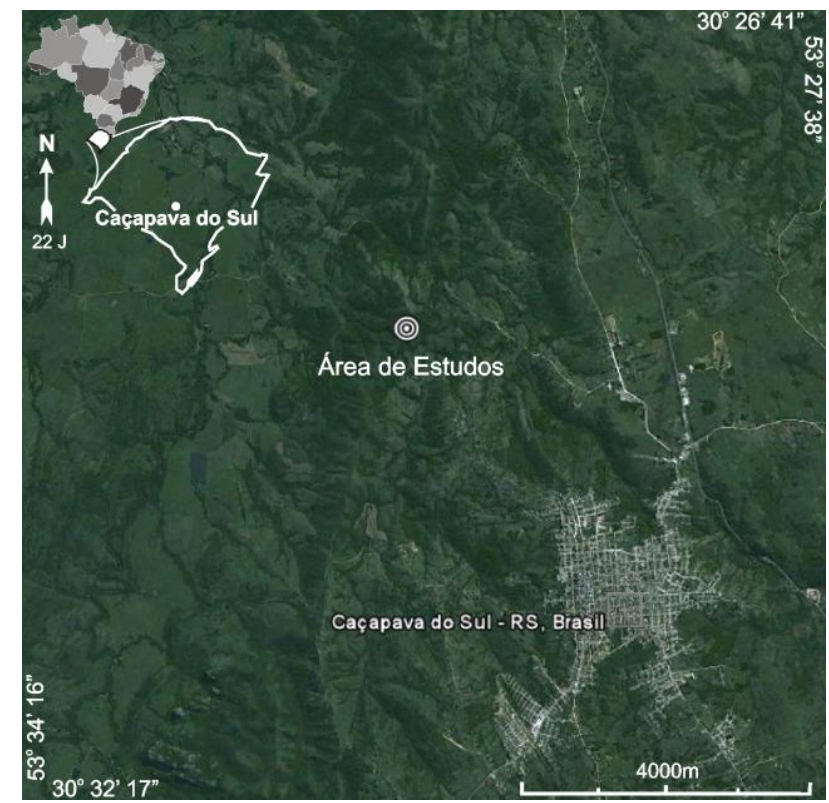

Figura 1 - Localização da área de estudos.

(Adaptado de Google Earth, 2010).

O município possui cerca de 33.060 habitantes (IBGE, 2009) com produção diária atual em torno de 12 toneladas de lixo doméstico.

A área de estudos foi utilizada durante 14 anos, entre 1980 e 1994. Durante esse período o lixão recebeu cerca de 28.000 toneladas de material, depositado à céu aberto, causando poluição ao meio ambiente e transtornos aos moradores próximos, devido a proliferação de insetos e mau-cheiro. Esta área é limitada a norte e a sul por duas drenagens.

Durante seu período de funcionamento, houve significa poluição destas águas, pois não havia quaisquer sistemas de coleta chorume (PMC,1996).

O contexto geológico da área compreende rochas do Complexo Metamórfico Vacacaí, constituído por uma unidade vulcânica (NP2vcv) e uma unidade vulcanosedimentar (NP2vcs) (CPRM, 2008). O Complexo é limitado principalmente por coberturas vulcanosedimentares não metamórficas e intrudida por granitos sintranscorrentes, tardi a pós-tectônicos.

A Suíte Granítica Caçapava do Sul compreende dois corpos graníticos intrusivos no Complexo Metamórfico Vacacaí. O corpo maior possui uma forma ovulada cujo eixo maior, com cerca de $25 \mathrm{~km}$ de extensão, está orientado segundo uma direção N-S, e denomina à suíte. Esta suíte é constituída dominantemente de monzo e sienogranitos com participação subordinada de rochas de composição granodiorítica a tonalítica representadas principalmente na borda oeste do corpo (CPRM, 2000).

O Complexo Metamórfico Vacacaí é localmente caracterizada por anfibolitos, mica-xistos e talco-xistos. A área de pastagem adjacente ao aterro apresenta exposições de granito e contato discordante com xistos do complexo metamórfico. O granito apresenta feições de metamorfismo, bandamento pouco pronunciado, cristais de coloração rosa. O fraturamento observado nos xistos possui prolongamento para o granito.

\section{Método}

O método da Eletrorresistividade emprega uma corrente elétrica artificial que é introduzida no terreno através de dois eletrodos (denominados de A e B), com o objetivo de medir o potencial gerado em outros dois eletrodos (denominados de M e N) (Lowrie,2007).

A resistividade elétrica está relacionada aos mecanismos de propagação de corrente elétrica nos materiais. Em geral, a propagação de corrente elétrica em solos e rochas ocorre devido ao deslocamento de íons dissolvidos na água contida nos poros e fissuras, sendo afetada principalmente pela composição mineralógica, porosidade, teor em água, quantidade e natureza dos sais dissolvidos (ELIS, et. al. 2004).

Este trabalho adota a técnica de caminhamento elétrico usada para determinar variações verticais de resistividade em duas dimensões (LOWRIE, 2007). O presente trabalho aplica 0 arranjo de campo dipolodipolo, que consiste em dois pólos de leitura de corrente e dois pólos de leitura de potencial, o espaçamento entre os eletrodos de corrente e potencial é constante.

Para a aquisição de dados foram realizadas 11 linhas de com espaçamento de $10 \mathrm{~m}$ entre elas. As linhas de caminhamento elétricos 1 a 7 foram realizadas sobre a áreas de resíduos enterrados. A linha 8 foi realizada no limite do aterro e as linhas 9 a 11 foram realizadas numa área de pastagem lateral ao aterro (Figura 2).

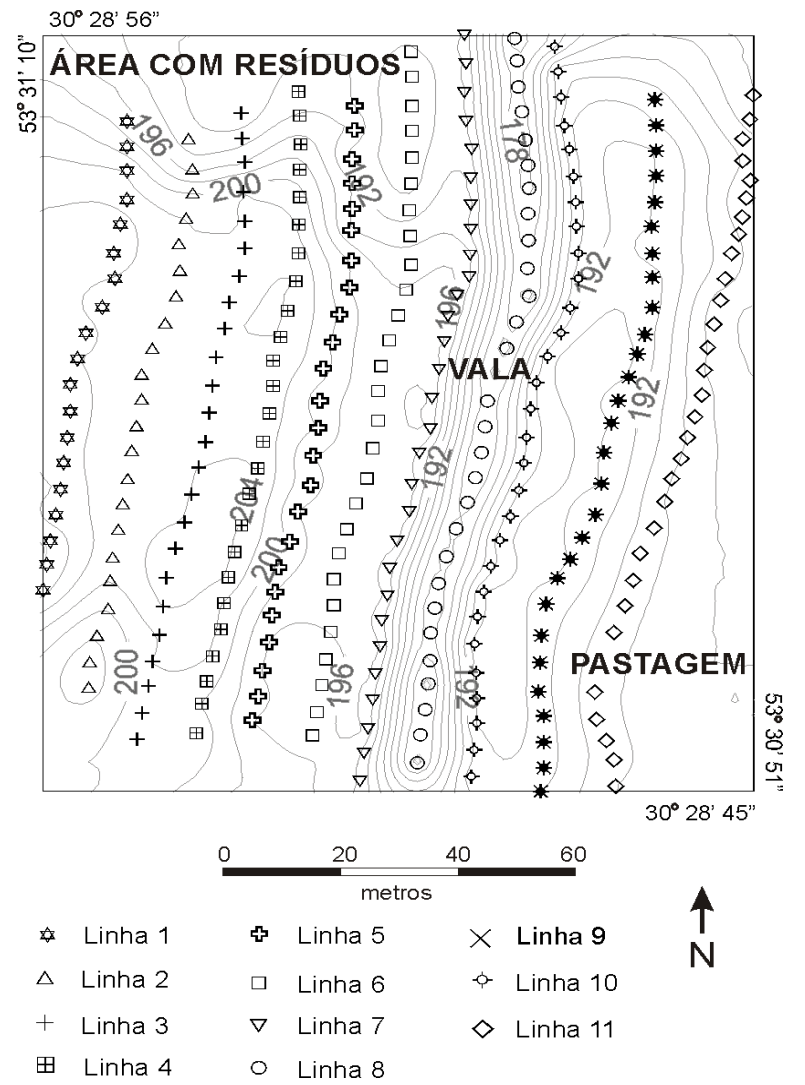

Figura 2 - Linhas de caminhamento elétrico com pontos de leitura e topografia da área. 
Foi adotado espaçamento de $5 \mathrm{~m}$ entre eletrodos e investigação de 10 níveis de profundidade. Foram realizadas 83 medidas de direção e sentido de fraturas, em exposições de rochas aflorantes no início e no final das linhas de caminhamento. Foi utilizado o resistivímetro SYSCAL PRO fabricado pela Íris Intruments (França), este equipamento realiza leituras de resistividade elétrica, cargabilidade elétrica e voltagem.

Os dados foram processados no programa RES2DINV (Loke \& Barker, 1996).

\section{Resultados e Discussão}

Os dados estruturais estão representados na forma de estereograma (Figura 3). O diagrama indica o predomínio de direções de fraturas entre $\mathrm{N} 0^{\circ}$ a $\mathrm{N} 110^{\circ}$ e mergulho de $90^{\circ}$.

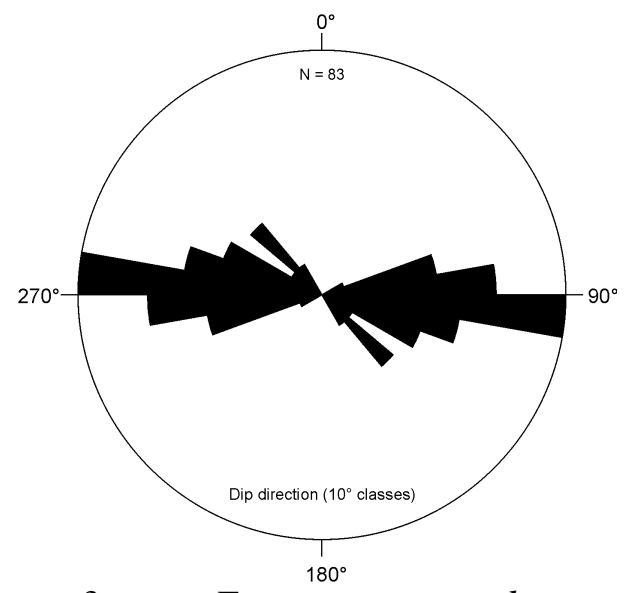

Figura 3 - Estereograma de medidas estruturais.

As linhas de caminhamento elétricos 1 a 7 foram realizadas sobre a áreas de resíduos enterrados. A linha 8 foi realizada no limite do aterro, numa vala que direciona o fluxo da água superficial para uma drenagem localizada no limite norte do aterro. As linhas 9 a 11 foram realizadas numa área de pastagem lateral ao aterro (Figura 2).

Com base nas informações de campo referentes à espessura de lixo em diversos pontos da área é possível afirmar que nas seções modeladas a faixa de valores entre $0 \Omega . \mathrm{m}$ e $70 \Omega . \mathrm{m}$ define o intervalo desde a superfície ate a base da camada de lixo, e que valores superiores a $70 \Omega$.m definem os anfibolitos e xistos presentes na região estudada (Figura 4 ).

Em campo foi comprovado que a espessura de lixo aumenta gradativamente de oeste para leste. As seções corroboram este fato, pois há um aumento da espessura da faixa de baixos valores de resistividade também de oeste para leste (Figura 4).

Algumas seções indicam anomalias verticais de baixa resistividade no intervalo atribuído à presença de rocha. Em grande parte das seções a uma faixa coincidente, em torno de $60 \mathrm{~m}$ do inicio da linha. Em campo foram verificadas fraturas com direções que variam de $70^{\circ}$ a $140^{\circ}$ e mergulho de $90^{\circ}$ (Figura 3 ). Desta forma, essas anomalias provavelmente descrevem a percolação de chorume em fraturas.

A linha 8 também é caracterizada por baixos valores de resistividade, embora esteja localizada no limite do aterro, numa área com ausência de resíduos. Entretanto, esta linha esta posicionada na parte mais baixa do aterro. É provável que esta linha receba um grande aporte de chorume proveniente das áreas elevadas, ou seja, as áreas cruzadas das linhas 1 a 7. Desta forma, os baixos valores de resistividade presentes na linha 8 devem estar associados a presença de chorume.

As linhas 9 a 11 foram realizadas fora do aterro. A partir da linha 11 há um desnível topográfico sentido a linha 8.

Linha 9 e 10 não é caracterizada por chorume ou presença de resíduos. Portanto, os valores baixos podem indicar presença de água.

Linha 11 apresenta resistividade maior em relação às linhas anteriores, pode estar associado à topografia mais elevada.

\section{Conclusões}

A aplicação do método de Eletrorresistividade na área de estudos permitiu caracterizar o intervalo com resíduos enterrados e a rocha sotoposta, devido ao contraste. Foi comprovado que a espessura de lixo aumenta gradativamente de oeste para leste. As seções corroboram este fato, pois há um aumento da espessura da faixa de baixos valores de resistividade também de oeste para leste.

Os resultados revelam baixos valores no intervalo de presença de resíduos, corroborados em trabalhos anteriores (MOREIRA et. al., 2009; MOURA \& MALAGUTTI, 2003). O intervalo atribuído a rocha é caracterizado por altos valores de resistividade, devido ao caráter inalterado.

Os modelos de inversão apresentam anomalias verticais de baixa intensidade principalmente nas posições de $60 \mathrm{~m}$ e $120 \mathrm{~m}$, associadas à presença de fluidos em planos de fraturas, identificadas em campo por meio de medidas estruturais.

Os resultados obtidos neste trabalho foram eficazes para este tipo de estudo, pois há uma relação entre baixos valores de resistividade com a presença de líquidos provenientes da degradação de materiais orgânicos, comprovado com trabalhos anteriormente aplicados.

\section{Referências}

CETESB. COMPANHIA DE TECNOLOGIA DE SANEAMENTO AMBIENTAL. 2001. Manual de gerenciamento de áreas contaminadas. GTZ. 2ª ${ }^{\mathrm{a}}$. Ed. São Paulo. 389p.

CPRM. Mapa Geológico do Estado do Rio Grande do Sul, Escala 1: 750.000. / organizado por Wilson Wildner; Gilberto Emílio Ramgrab; Ricardo da Cunha Lopes; Carlos Moacyr Fontoura Iglesias - Porto Alegre: CPRM, 2008.

CPRM. Programa Levantamentos Geológicos Básicos do Brasil. Cachoeira do Sul, Folha SH.22-Y-A. Estado do Rio de Grande do Sul. Escala 1:250.000. / organizado por 
Carlos Alfredo Porcher e Ricardo da Cunha Lopes. Brasília: CPRM, 2000.

ELIS V. R, BARROSO C. M. R, KIANG, C. H. 2004. Aplicação de ensaios de resistividade na caracterização do Sistema Aqüífero Barreiras / Marituba em Maceió AL. Rev. Brasileira de Geofísica, 22: 101 - 113.

GOOGLE EARTH. Versão 4.3 (beta). Europa Technologies - US Dept. of state Geographer, 2010.

HAMADA J. 1999. Estimativas de geração e caracterização do chorume em aterros sanitários. In: Congresso Brasileiro de Engenharia Sanitária e Ambiental, 19: 1999.

IBGE - Instituto Brasileiro de Geografia e Estatística. Disponível em: <www.ibge.gov.br>. Acesso em: 02/12/09.

JUCÁ J.F.T. 2003. Disposição Final dos resíduos sólidos urbanos no Brasil. In: Congresso Brasileiro de Geotecnia Ambiental. Porto Alegre: REGEO, 2003.

LOKE M.H. \& BARKER R.D., 1996. Rapid least-squares inversion of apparent resistivity pseudosections by a
quasi-Newton method. Geophysical Prospecting, 44: 131152.

LOWRIE, W. 2007 Fundamentals of Geophysics. 2. Ed. New York: Cambridge University Press, 381pp.

MOREIRA C. A, BRAGA A. C. O \& FRIES, M. 2009. Degradação de resíduos e alterações na resistividade elétrica, pH e Eh. Revista Brasileira de Geofísica, 27: 283 $-293$.

MOURA H. P, MAKAGUTTI F. 2003. Métodos de Eletrorresistividade e de Polarização Induzida aplicados na área de disposição de resíduos urbanos: Aterro Controlado de Rio Claro - SP. Geociências, 22: 129-139.

PMC - Prefeitura Municipal de Caçapava do Sul - Antigo Lixão. Relatório Final, 42 p, 1996.

POSSAMAI F.P, VIANA E, SCHULZ H.E, COSTA M.M, CASAGRANDE' $E$, 2007. Lixões inativos na região carbonífera de Santa Catarina: análise dos riscos à saúde pública e ao meio ambiente. Ciência \& Saúde Coletiva, 12:171-179.

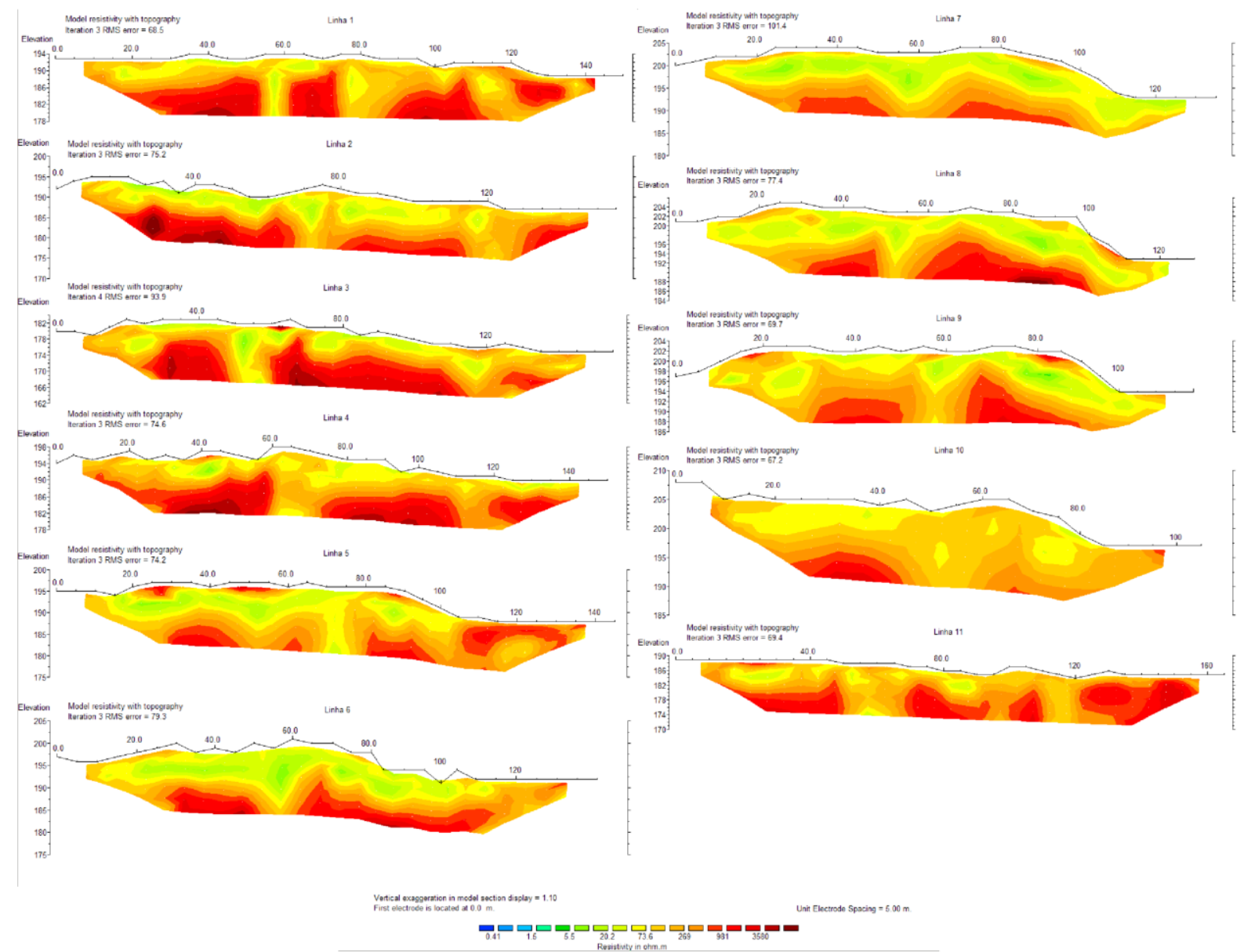

Figura 4 - Modelo de inversão em termos de Resistividade da linha 1 a 11 